\title{
Thanatophoric Dwarfism
}

\author{
K. SHAH, R. ASTLEY, and A. H. CAMERON \\ The Children's Hospital, Birmingham B16 8ET
}

\begin{abstract}
Summary. A review of the radiographs of children previously classified as achondroplasiacs revealed six thanatophoric dwarfs. The main radiological differentiating features were the greater degree of shortening of the long bones, including the fibula, the curvature of the femora, the very small size of the thorax and, particularly, the very narrow ossified elements of the vertebral bodies. Perhaps the most important aspect of differential diagnosis lies in recognition in utero. The reported association with clover-leaf deformity of the skull in sibs provides the strongest evidence for genetic differentiation from classical achondroplasia. More evidence might be obtained by a widespread search through hospital radiological museums.
\end{abstract}

Thanatophoric dwarfism is a severe form of micromelic dwarfing which usually results in death at or shortly after birth. This name, reflecting the fatal prognosis, was given in 1967 by Maroteaux, Lamy, and Robert, who first separated the condition from classical achondroplasia. They collected a total of 21 cases from 1898 to 1967 , including four of their own. Since then a number of cases has been reported in the literature and it appears that the condition is not extremely uncommon (Langer et al, 1969; Kaufman et al, 1970; Keats, Riddervold, and Michaelis, 1970; Kozlowski, Prokop, and Zybaczynski, 1970; Campbell, 1971).

\section{Material}

A review of our own children previously classified under the diagnosis of achondroplasia led to the discovery of six infants who fitted the description of Maroteaux et al (1967). Included is one child from the Birmingham Maternity Hospital by courtesy of Drs J. Bishop and J. Hutton. In addition one example was found of the related condition of achondrogenesis, to which reference will be made subsequently.

\section{Clinical and Pathological Features}

Table I summarizes some of the information about the six cases. Hydramnios was noted in two. Prematurity was not a feature. Birth weights ranged from 1.24 to $3.9 \mathrm{~kg}$ but only one was under $2 \cdot 25 \mathrm{~kg}$. Five had a breech presentation

Received 12 March 1973. and three had difficult labour, presumably because of the large head. One had a Caesarean section for pelvic disproportion. Four of the infants were stillborn, one lived for $3 \frac{1}{2}$ hours and one survived for one day. The longest recorded survival is 25 days according to Langer et al (1969). It is interesting that case 1 was the first of dichorionic dizygotic twins, the second being a normal baby. Two of the children were diagnosed radiologically as achondroplasiacs while in utero. There was no family history of generalized bone dysplasia.

There was severe micromelic dwarfing with deep soft-tissue folds in the limbs. Many of the features were common to classical achondroplasia, including a relatively large head with a short base of the skull, prominent forehead, relatively small face and depression of the bridge of the nose (Fig. 1). The neck was short but the trunk appeared to be of normal length. The thorax was narrow from side to side and the scapulae projected laterally. The abdomen usually showed moderate diffuse distension. There was hypotonia and the lower limbs were abducted and externally rotated. All four limbs showed marked shortening, involving the phalanges as well as the proximal and distal major segments.

Where the infant was not stillborn there was severe respiratory distress and early death. Table II shows the most important items from the necropsy reports. Two children, cases 3 and 4 , had abnormal skulls. In case 4 this was described as a 'huge, floppy dome' (Fig. 2). The squamous bones were 
TABLE I

\begin{tabular}{|c|c|c|c|c|c|c|}
\hline & \multicolumn{6}{|c|}{ Case } \\
\hline & 1 & 2 & 3 & 4 & 5 & 6 \\
\hline Maternal age & 27 & & 34 & 27 & 21 & 33 \\
\hline Para & 4 (first of twins) $*$ & 2 & Primiparous & 4 & 4 & 3 \\
\hline Hydramnios & & & & Yes & Yes & \\
\hline Gestation & 34 weeks & 38 weeks & ? 38 weeks & 40 weeks & 40 weeks & \\
\hline Presentation & Breech & Breech & & Breech & Breech & Breech \\
\hline Labour/delivery & $\begin{array}{l}\text { Prolonged 2nd } \\
\text { stage }\end{array}$ & $\begin{array}{l}\text { Difficult delivery } \\
\text { of head }\end{array}$ & $\begin{array}{c}\text { Caesarean (pelvic } \\
\text { disproportion) }\end{array}$ & Difficult & Normal & \\
\hline Other features & $\begin{array}{l}\text { Poor condition; } \\
\text { severe asphyxia }\end{array}$ & & $\begin{array}{l}\text { Severe } \\
\text { respiratory } \\
\text { distress }\end{array}$ & & & \\
\hline Age at death & $3 \frac{1}{2}$ hours & Stillborn & 1 day & Stillborn & Stillborn & Stillborn \\
\hline
\end{tabular}

* Twin 2 was normal (1,850 g); dichorionic, dizygotic.

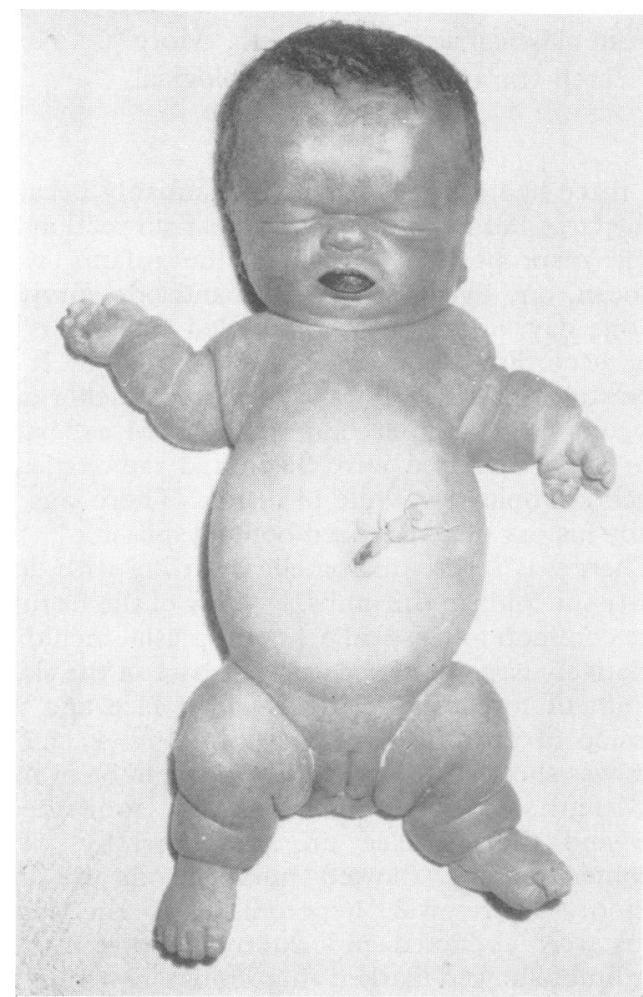

Fig. 1. Case 2. The limbs are short and show transverse creases. The neck is short, the chest narrow, and the abdomen protuberant.

thin and showed several membranous defects and birth fractures associated with haemorrhage into the scalp. The sutures and fontanelles were wide. The posterior fossa was small and the anterior part of the cranial cavity was asymmetrical with gross elevation

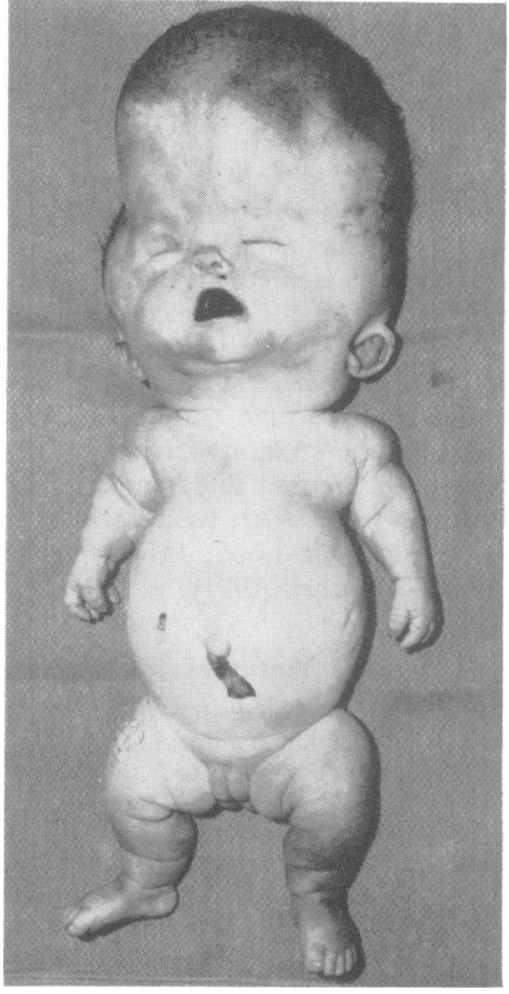

Frg. 2. Case 4. Atypical thanatophoric dwarf with gross hydrocephalic enlargement of the head.

of the lesser wing of the sphenoid on the left and deviation of the falx cerebri to the left anteriorly. The brain showed areas of microgyria and pachygyria, with gross dilatation of the lateral and third ventricles. The upper part of the aqueduct was 
TABLE II

\begin{tabular}{|c|c|c|c|c|c|c|}
\hline & \multicolumn{6}{|c|}{ Case } \\
\hline & 1 & 2 & 3 & 4 & 5 & 6 \\
\hline Necropsy no. & $67-202$ & $59-321$ & $66-308$ & $60-396$ & $59-282$ & M.H. \\
\hline $\begin{array}{l}\text { Short limbs with } \\
\text { prominent folds }\end{array}$ & Yes & Yes & Yes & Yes & Yes & Yes \\
\hline Large head & Yes & Yes & Yes & $\begin{array}{l}\text { Yes; 'huge, } \\
\text { floppy dome' }\end{array}$ & Yes & Yes \\
\hline Large fontanelles & No & $\begin{array}{l}\text { Yes (including } \\
\text { third) }\end{array}$ & $\begin{array}{l}\text { Yes; abnormal } \\
\text { skull }\end{array}$ & $\begin{array}{l}\text { Abnormal skull; } \\
\text { thin bones; } \\
\text { membranous } \\
\text { defects }\end{array}$ & Yes & Yes \\
\hline Hydrocephalus & No & No & No & $\begin{array}{l}\text { Yes (aqueduct } \\
\text { stenosis) }\end{array}$ & $\begin{array}{l}\text { Yes (non- } \\
\text { obstructive) }\end{array}$ & \\
\hline Small foramen magnum & & Yes & Yes & Yes & & \\
\hline Other features & $\begin{array}{l}\text { Tentorial } \\
\text { laceration; } \\
\text { bilobed lung; } \\
\text { coarctation } \\
\text { and patent } \\
\text { ductus } \\
\text { arteriosus }\end{array}$ & $\begin{array}{l}\text { Subdural and } \\
\text { adrenal } \\
\text { haemorrhage; } \\
\text { absent right } \\
\text { umbilical } \\
\text { artery }\end{array}$ & $\begin{array}{l}\text { Fused saggital } \\
\text { suture; } \\
\text { asphixial } \\
\text { haemorrhage }\end{array}$ & $\begin{array}{l}\text { Macrogyria and } \\
\text { patchy } \\
\text { microgyria }\end{array}$ & $\begin{array}{l}\text { Brain over- } \\
\text { weight }\end{array}$ & Macerated fetus \\
\hline
\end{tabular}

Birth weights ranged from 1240 to $3900 \mathrm{~g}$.

dilated but its lower part appeared obstructed; this was probably due to compression by upwards herniation of cerebellum from the small posterior fossa, as there was no atresia histologically.

One other child, case 5, also had hydrocephalus (of a non-obstructive type) but three others, including case 3 with an abnormal skull, did not have large ventricles or developmental anomalies of the brain. In three babies a small foramen magnum was recorded, a feature that is also seen in achondroplasia. Case 1 had coarctation of the aorta with a persistent ductus arteriosus. There were no other associated malformations of the viscera, except for the lungs which were characteristically underweight. The hypoplasia appeared to be due to the reduced volume of the thorax; the cavity of the latter was extremely narrow because of the shortening of the ribs and it was largely occupied by the vertebral column.

\section{Radiology}

There was a great similarity of radiological appearances in all the children (Figs. 3 and 4). The trunk was normal in length but the long bones were very short with irregular, somewhat flared ends and quite pronounced curvatures, especially constant in the femora. The shortening of the long bones was greater than in achondroplasia, where curvature is not a common or pronounced feature. There was a 'spiky' appearance at the edges of bone-cartilage junctions, eg, at the medial and lateral aspects of the irregular epiphyseal lines and at the inferior angle of the scapula. The fibula was not longer than the tibia as is usual in achondroplasia. The upper ends of the femur and humerous showed the same sort of oval translucency that is seen in achondroplasia, with a narrow shelf projecting to produce the white line demarcating the lower end of the translucency. In Fig. 3 the left humerus is seen in a roughly

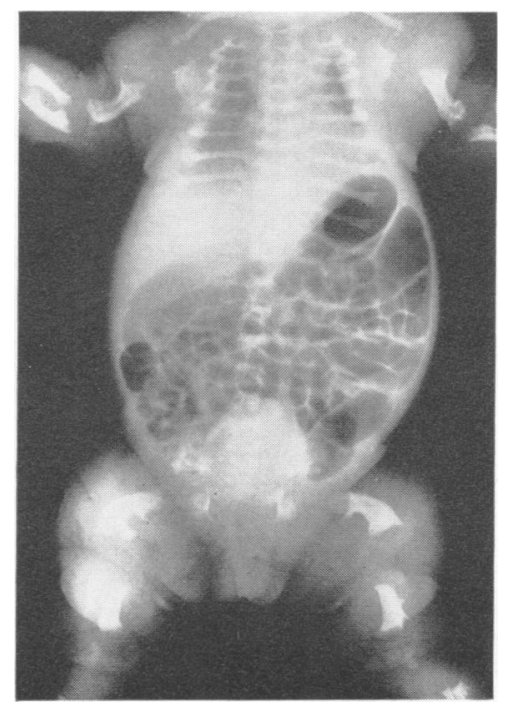

Fig. 3. Case 2. 
anteroposterior position and demonstrates the translucent area at its upper end. The projection of the right humerus is more lateral and the thin upper end of the humerus that accounts for the translucency, with the narrow shelf projecting forwards, can be seen. At the upper end of the femur the similar shelf projects posteriorly.

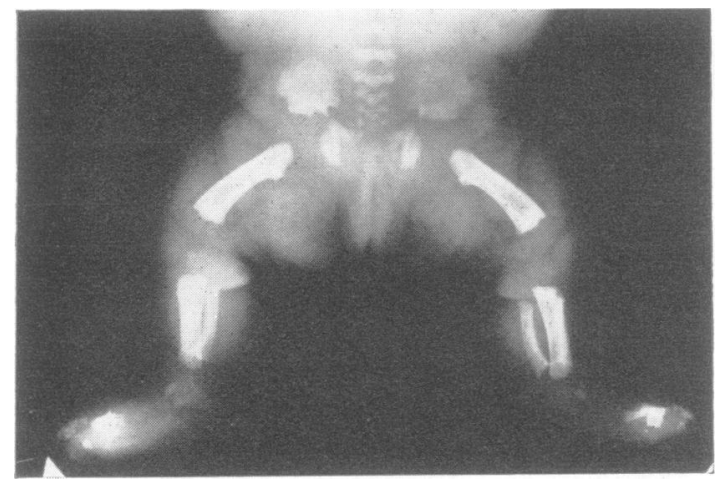

Fig. 4. Case 4.

The joint spaces appeared wide, a manifestation of the enlargement of the cartilaginous ends of the long bones which in necropsy specimens produced a dumb-bell appearance.

The ossified parts of the vertebral bodies were notably narrow in their supero-inferior diameter

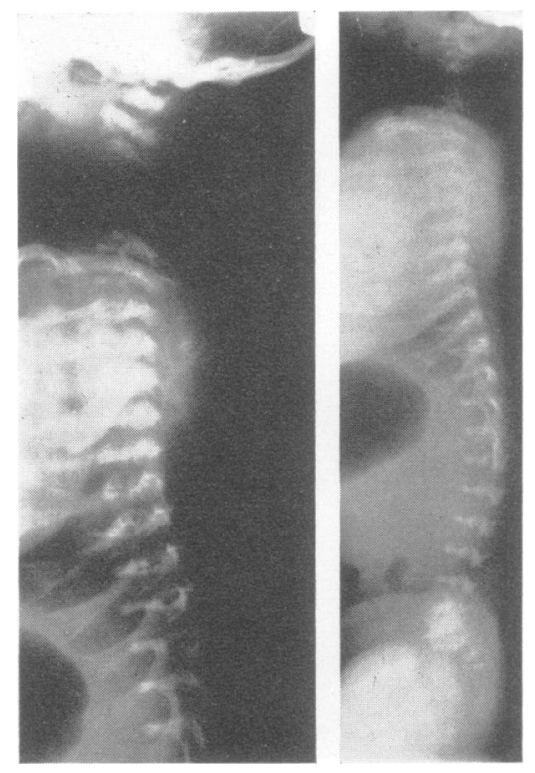

Fig. 5. Case 3. with relatively wide interspaces and normal-sized arches (Fig. 5). Necropsy examination showed that the remaining parts of the vertebral bodies, consisting of unossified cartilage, were increased, while the disc spaces, despite their radiological appearance, were normal in width. The radiological appearances contrasted with the much more square or 'bullet-shaped' vertebral bodies of achondroplasia. The vertebrae tended to be a little narrower in the middle of their bodies and their posterior borders were concave. The anterior height of the bodies was a little greater than the posterior height in the upper spine while the reverse was true at the lower end. As in achondroplasia the anteroposterior diameter of the spinal canal was narrow and the interpedicular distance, on passing downwards from the thoracic region, was seen to decrease (or, at least, not to increase) towards the sacrum.

The thorax was small and the ribs were very short $\vec{\omega}$ with expanded, concave anterior ends. The cla- 을 vicles were normal in length, appearing relatively long in comparison with the ribs. Sternal ossi- $D$ fication centres were absent or rudimentary. The pelvic appearances (see Fig. 4) were very similar to those of achondroplasia, with a square ilium and a flat acetabulum. Langer et al (1969) have stated that the ilium is more square in achondroplasia while in thanatophoric dwarfism it is wider in the transverse diameter than it is vertically. This was not a definite differentiating feature in our patients

In case 4 , where the head was described at necropsy as having a 'huge, floppy dome', the skull was large with elongation vertically. It was grossly deformed with poor ossification, wide sutures and multiple membranous defects (Figs. 6a and 6b). The occipital bone was irregular on its inner aspect with thickened ridges enclosing areas of thinning. The sphenoid on the left rose into a high ridge between the anterior and middle cranial fossae. In case 3, the other child with an abnormal skull, it was also elongated vertically with lacunar formation. The metopic suture was wide with a large anterior fontanelle, but fusion of the parietals in the midline. The occipital bone was small. The skull was widened asymmetrically. It was wide in the anterior fossa, but narrow in the posterior fossa, with some suggestion of a clover-leaf shape.

\section{Histology}

Material from four cases of thanatophoric dwarfism has been subjected to pathological review. The macroscopic and histological appearances of the skeletal system have been compared with cases of achondroplasia, metatropic dwarfism, achondro- 

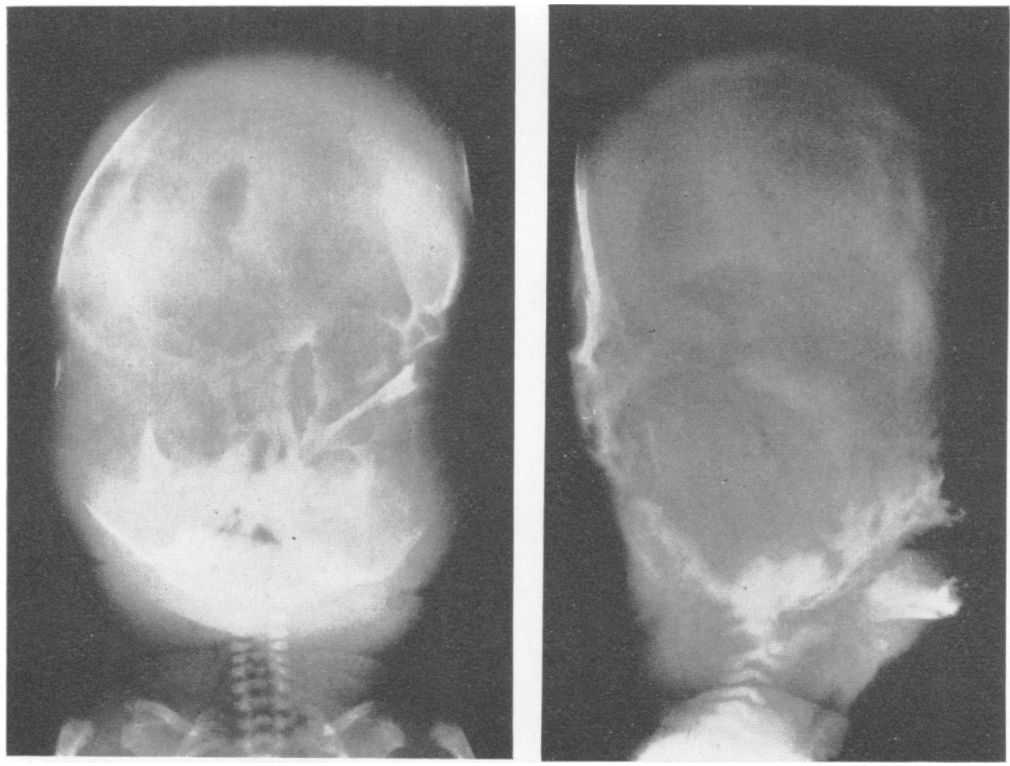

Fig. 6a and b. Case 4.

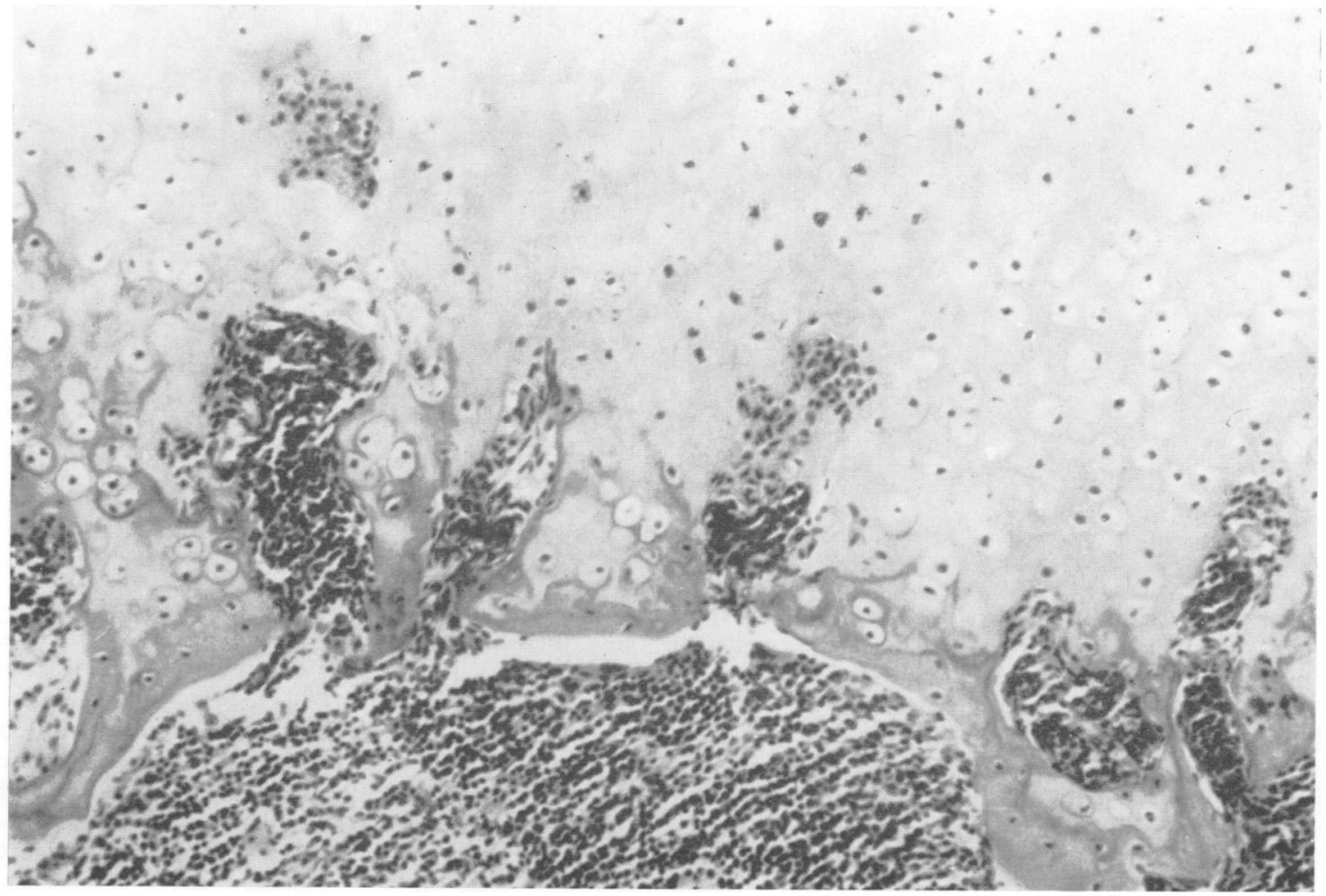

FIG. 7. Case 3. Grossly retarded ossification. There are no regular columns of cartilage cells and the calcified cartilage is much increased. Plates of osteoid lie transversely across the surface of the epiphyseal plate. (Lower femur, $\mathrm{H} \& \mathrm{E}, \times 190$.) 




FIG. 8. Case 1. Costochondral junction showing retarded ossification and, at either side, a cuff of periosteal bone overlapping the cartilage (H \& E, $\times 19)$.

genesis, the Ellis-van Creveld syndrome and osteogenesis imperfecta, as well as with necropsy material from babies without any skeletal disorder. In most cases blocks from the vertebral column, costochondral junctions and from at least one long bone have been examined. As a routine the material was fixed in formalin, decalcified in formic acid, and stained with haematoxylin and eosin. Some sections were viewed in polarized light and a few undecalcified blocks were stained by von Kossa's method as well as haematoxylin and eosin.
There was gross retardation of the normal process of cartilaginous maturation (Fig. 7). This was most evident in the long bones where the process is normally most active. The cartilage cells failed to form regular columns and showed only limited $\sigma$ swelling of their cytoplasm. As a consequence $N$ there was more intercellular matrix than normal and $N$ this became calcified in the usual way. The cartilaginous plate at the epiphysis showed short blunted processes and, indeed, often a completely flat, inactive surface. Ossification necessarily $\stackrel{\mathcal{S}}{\rightarrow}$ 


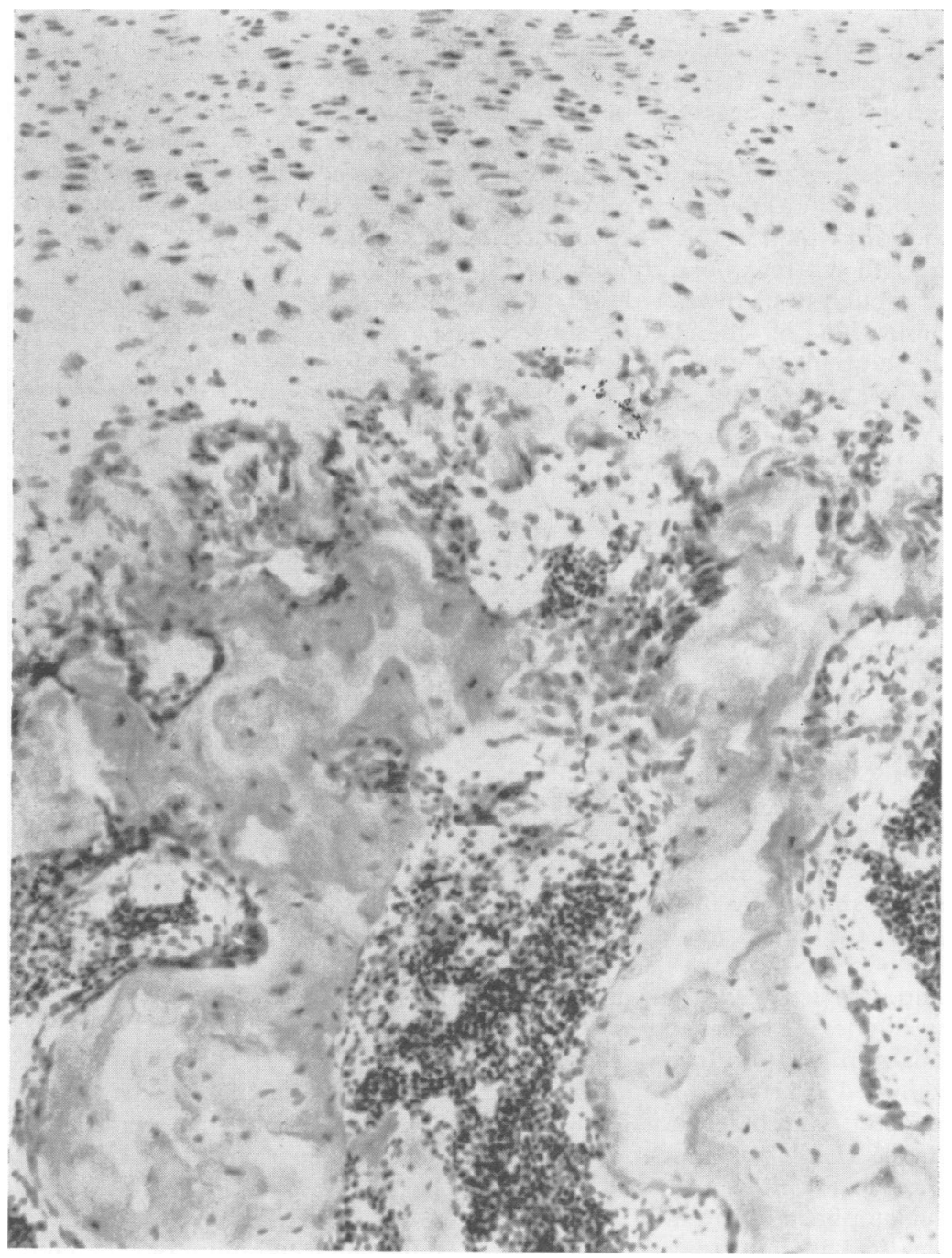

FIG. 9. Case 4. Retarded ossification; the changes are similar to those in Fig. 6a. (Upper humerus, H \& E, $\times 190$ ).

followed the same abnormal pattern. There were focal differences in the degree of pathological change. It was not unusual to see a small turret of calcified cartilage projecting into the mataphysis; this was due to complete cessation of activity in this segment while on either side activity was only moderately reduced. Similar irregularities were not uncommon at the costochondral junctions and another feature which was particularly well seen here was the formation of cuffs of periosteal bone on either side of the cartilage (Fig. 8), corresponding to the radiological 'spikes'. These were due to the absence of retardation of periosteal ossification (which requires no preliminary maturation of cartilage) so that periosteal bone outstripped ossification of the cartilage.

The histological changes varied greatly from bone to bone as well as in different segments of the same bone. Similar features were encountered in achondroplasia, metatropic dwarfism, achondrogenesis and the Ellis-van Creveld syndrome. To distinguish these conditions it was essential to evaluate the complete picture, particularly the external features and the pattern of radiological changes.

Case 4 (see Figs. 2 and 6) needs special mention because of the associated abnormalities of both skull 
and brain. In this child the shortening of the limbs was slightly less marked and the long bones were not so dumb-bell shaped; the cartilaginous ends were less bulbous and appeared to be more in proportion to the shaft. The vertebral bodies showed larger ossific centres than did the other cases. The sternum also showed a different configuration, being shorter and thicker than in the other children and showing two small centres of ossification which were at least large enough to be measured $(1.5 \mathrm{~mm})$. Histological examination of the bones showed changes similar to those in the other thanatophoric cases but generally less severe (Fig. 9).

\section{Discussion and Differential Diagnosis}

In the past, thanatophoric dwarfism was confused with classical achondroplasia and the infants were considered to be very severely affected or very immature achondroplastic dwarfs. However, the suggestion of immaturity can be dismissed because many of the thanatophoric dwarfs that have been described, including four of our own cases, were born at, or very near, full term.

The arguments for differentiating the two conditions are in two groups, radiological and genetic. Firstly, despite the radiological similarities there are also radiological differences. Essentially these are the greater degree of shortening of the long bones, including the fibula, the curvatures of long bones, possibly the shape of the pelvis, the very small size of the thorax and, particularly, the very narrow ossified elements of the vertebral bodies. Among the achondroplasiacs in our film library there are a few that were examined as infants. Amongst these the proportions of the vertebrae varied somewhat and in one instance there was moderate superoinferior narrowing but no child showed such narrow bodies as the thanatophoric dwarfs. Langer et al (1969) have stated that homozygous achondroplasiacs, where both parents are affected and in whom the disease might reasonably be expected to be seen in its most severe form, do in fact tend to be reminiscent of thanatophoric dwarfs, but they still resemble achondroplasia more than they do thanatophoric dwarfing.

As mentioned previously, our review also revealed one case of the rare condition that has been called achondrogenesis (Fig. 10) described by Parenti in 1936 and more recently reviewed by Saldino (1971). This condition has many features similar to both achondroplasia and thanatophoric dwarfism, but the main differentiating feature is the absence of ossification in the lower vertebral bodies and in the ischium and pubis. It shares with thanatophoric dwarfism the radiological appearance of very narrow vertebral bodies.

Another condition in which such narrow vertebrae are seen is metatropic dwarfism. Here the child does not necessarily die soon after birth, although there is a considerable mortality in the early months, and there is dwarfism with short limbs but long hands and feet. The shortened bones show

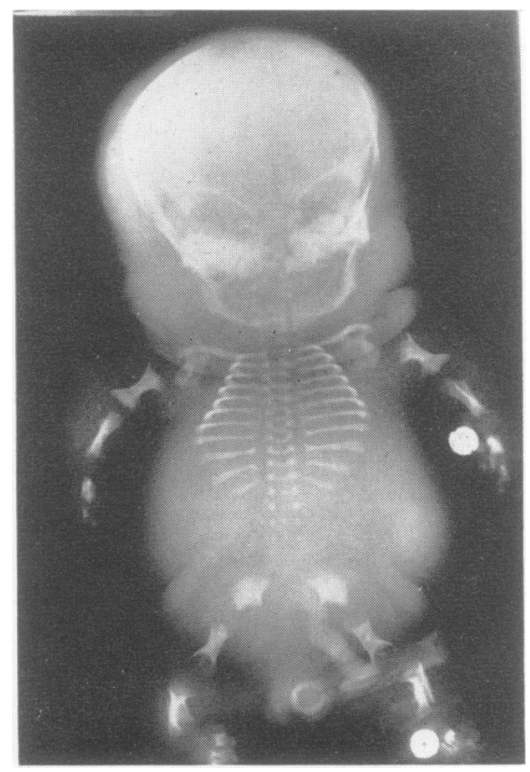

FIG. 10. Achondrogenesis.

expanded, cupped ends with an even more 'spiky' appearance than that seen in thanatophoric dwarfism at the margins of the bone ends and other bonecartilage transitions such as at the ischium and at the inferior angle of the scapula. The pelvis has the same flat acetabulum but the ilium is more rounded. The vertebrae are slightly less flat, with a more rounded shape anteriorly and they are smaller posteriorly (Fig. 11). The bodies may be divided in the coronal plane and also in the saggital plane. There may be a tail-like fold of skin over the coccyx. There are wide cartilaginous gaps at the costovertebral joints. The bodily proportions due to the short limbs but long thorax that are seen at birth are altered later with the progression of a severe kyphoscoliosis (Gefferth, 1973).

In asphyxiating thoracic dystrophy, which has the same liability to cause early death, the spine is normal. Other forms of short-limbed dwarfism do not closely resemble thanatophoric dwarfism and are easy to differentiate on the basis of clinical and 

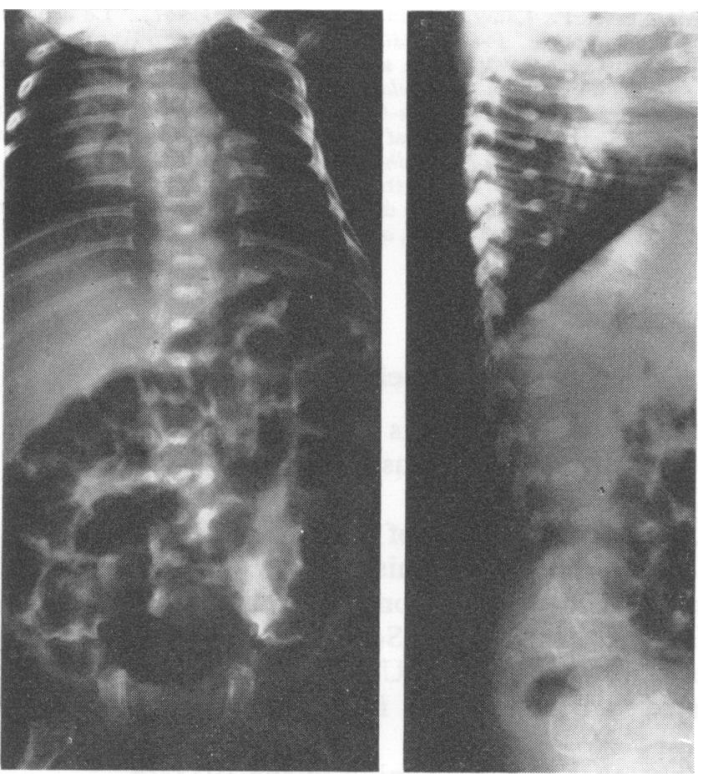

FIG. 11. Metatropic diwarfism.

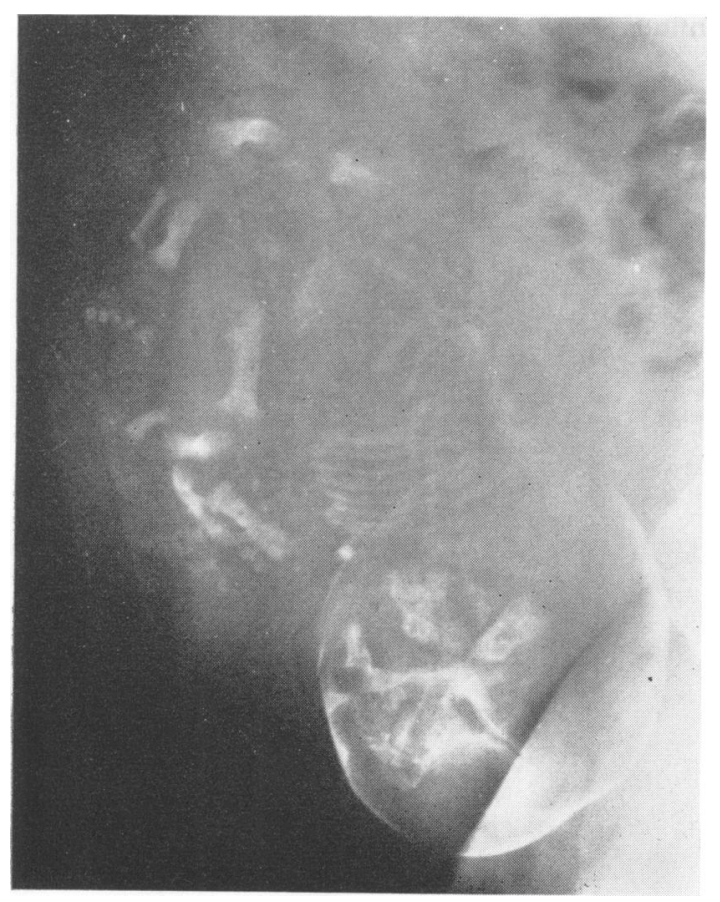

Fig. 12. Case 6, in utero. radiological findings. Perhaps the most important aspect in differential diagnosis lies in recognition in utero. Here the features most likely to be detected are the curvature of the short femora and the narrow vertebral bodies (Fig. 12).

It can be argued that the radiological changes in thanatophoric dwarfism are essentially a quantitative modification of those seen in classical achondroplasia, representing a more severe degree, as might well be expected in those that die of the disease. This view could coincide with the histological findings. Thus there is considerable importance in the second group of differences between the two conditions, namely the genetic aspects.

Classical achondroplasia has a dominant inheritance but most cases occur as apparently spontaneous mutations in children born to normal parents. Therefore the finding of thanatophoric dwarfism in sibs would be strong evidence that it is a different condition. On the other hand, if it could be shown that an achondroplasiac parent had given birth to a thanatophoric dwarf it would be a good argument against differentiation of the two conditions. Langer et al stated in 1969 that there is no known instance of this occurring. However, perhaps too few children born to achondroplasiac parents have been studied and perhaps the total of recognized cases of thanatophoric dwarfism is still too small for this to be a strong argument. Partington et al (1971) described four children in whom clover-leaf deformity of the skull was associated with thanatophoric dwarfism. They stated that there is a total of 13 such cases in the literature and the two cases in the present series with cranial deformity might possibly be included in this same category. It is important to note that two of Partington's cases were sibs. If these children are accepted as true examples of thanatophoric dwarfism it is strong support for the view that thanatophoric dwarfism is not due to a lethal dominant mutation.

As the thanatophoric dwarfs reported in this paper were discovered by a search through the departmental museum of radiographs, it does seem that similar searches in other hospitals would unearth a considerable total of cases. These might include examples of thanatophoric dwarfism amongst sibs or possibly even thanatophoric dwarfs and achondroplasiacs in the same family and the cumulative data might convincingly solve the problem.

\section{REFERENCES}

Campbell, R. E. (1971). Thanatophoric dwarfism in utero. American Fournal of Roentgenology, Radium Therapy, and Nuclear Medicine, 112, 198-200.

Gefferth, K. (1973). Metatropic dwarfism. In Progress in Pediatric Radiology, vol. 4. Karger, Basel. 
Kaufman, R. L., Rimoin, D. L., McAlister, W. H., and Kissane, J. M. (1970). Thanatophoric dwarfism. American fournal of Diseases of Children, 120, 53-57.

Keats, T. E., Riddervold, H. O., and Michaelis, L. L. (1970). Thanatophoric dwarfism. American fournal of Roentgenology, Radium Therapy, and Nuclear Medicine, 108, 473-480.

Kozlowski, K., Prokop, E., and Zybacznski, J. (1970). Thanatophoric dwarfism. British fournal of Radiology, 43, 565-568.

Langer, L. O., Spranger, J. W., Greinacher, I., and Herdman, R. C. (1969). Thanatophoric dwarfism. Radiology, 92, 285-294.
Maroteaux, P., Lamy, M., and Robert, J. M. (1967). Le nanisme thanatophore. Presse Médicale, 75, 2519-2524.

Parenti, G. C. (1936). La anosteogenesi (un varietà dell' osteogenesi imperfetta). Pathologica, 28, 447-461.

Partington, M. W., Gonzales-Crussi, F., Khakee, S. G., and Wollin, D. G. (1971). Cloverleaf skull and thanatophoric dwarfism. Archives of Disease in Childhood, 46, 656-664.

Saldino, R. M. (1971). Lethal short-limbed dwarfism: achondrogenesis and thanatophoric dwarfism. American fournal of Roentgenology, Radium Therapy, and Nuclear Medicine, 112, 185-197.

\section{The Scheinfeld Center for Human Genetics in the Social Sciences}

The growing interest in human genetics among social scientists has prompted the establishment of a new centre at The Hebrew University of Jerusalem, through the medium of the American Friends of The Hebrew University.

Endowed by Mrs Aaron Scheinfeld of Chicago in memory of her late husband (who was chairman of Manpower Inc), and in honour of his brother Amram (author of many books on human genetics), the new educational unit has been named the 'Scheinfeld Center for Human Genetics in the Social Sciences'. It will be affiliated with the Faculty of Social Sciences of the Hebrew University, but will cooperate in its activities with all interested departments or individuals at the Hebrew University or elsewhere.

The Centre, which formally opened in November at the begining of the 1973/74 academic year, will offer courses and seminars in human genetics especially oriented towards students of psychology, sociology, anthropology, and education. It will also subsidize research in such areas as human behavioural genetics, sex-differences, twin studies, human growth and development, and physical features. The underlying emphasis will be on normal traits and behaviour, as distinguished from pathological conditions, and on clarifying the interacting influences of heredity and environment in producing variation among human beings. 